MARÍA ANGELS FORTEA CASTILLO

GRACMON - GRUPO DE INVESTIGACIÓN

EN HISTORIA DEL ARTE Y DEL DISEÑO

CONTEMPORÁNEOS

UNIVERSIDAD DE BARCELONA

BARCELONA, ESPAÑA

MANGELS.FORTEA@BAUED.ES

El artículo es producto de la investigación

realizada para la tesis doctoral de la autora.

(Fortea Castillo, 2015).

Fecha de recepción: 02/05/2017

Fecha de aceptación: 30/06/2017

Cómo citar: Fortea Castillo, M. A. (2017). El Pop

como expresión gráfica de la resistencia cultural catalana. RChD: creación y pensamiento, 2(2). 1-15

DOI: 10.5354/0719-837X.2017.46133

Revista Chilena de Diseño,

RChD: creación y pensamiento

Universidad de Chile

2017, 2(2)

http://rchd.uchile.cl

\section{El Pop como expresión gráfica de la resistencia cultural catalana}

The Pop as a Graphic Expression of the Catalan Cultural Resistance

Resumen. En los años sesenta, en Cataluña (España) una de las formas de oposición pacífica contra la dictadura de Franco y sus directrices culturales fue la puesta en marcha de una renovada industria cultural. Como resultado se asistió a la aparición de una importante producción cultural en lengua catalana de gran calidad, al punto que el estilo Pop se convirtió, en el año 1968, en la expresión gráfica de la resistencia cultural. Las discográficas de nuevo cuño, fundadas en el momento en que la canción popular se convirtió en el mejor medio de difusión del catalán, fueron las primeras en aplicar los rasgos del Pop, de clara influencia norteamericana, evolucionando con el tiempo hacia una versión autóctona que recuperó la tradición gráfica de Cataluña.

Palabras clave: Cataluña, discográficas, gráfica Pop, industria cultural, resistencia cultural.

Abstract. In the 1960s, the implementation of a renewed cultural industry took place in Catalonia (Spain) as a tool of peaceful action in opposition to Franco's dictatorship and its cultural guidelines. As a result, an important cultural production was developed, in Catalan language, applying the Pop Style. By 1968 it became the formal language of the cultural resistance. New record labels were founded at the time when the popular song became the most effective media of the Catalan language. They were the first to apply the Pop style, with a clear American influence, evolving over time towards a native version of Pop that rediscovered the Catalan graphic tradition.

Keywords: Catalonia, record labels, Pop graphics, cultural industry, cultural resistance. 
1. Un dominio más amplio de investigación re-

queriría de una mayor extensión de texto, lo cual no significa que el estilo Pop no se aplicara también en el sector editorial, sino muy al contrario.

2. America Sanchez, sin acentos como él lo escribe, es uno de los referentes del diseño gráfico catalán desde su llegada a Barcelona en el año 1965. Ha sido reconocido con el Premio Nacional de Diseño de 1992 por su trayectoria profesional.

3. Enric Satué es otro de los grandes diseñadores gráficos catalanes, destacando no sólo por sus proyectos sino también por su faceta como escritor, recuperando la historia del diseño gráfico local y nacional. Fue galardonado con el Premio Nacional de Diseño en el año 1988.

\section{INTRODUCCIÓN}

En Cataluña (España), la cultura se convirtió en una de las herramientas de acción pacífica contra la dictadura de Franco y sus directrices culturales. Por ello, desde principios de los años sesenta se relanzó una importante y renovada industria cultural, cuyo objetivo principal fue conseguir la normalización del uso del catalán como lengua vehicular, así como promocionar la cultura y la identidad nacional catalanas. Hay que anotar que el catalán estuvo prohibido por el régimen franquista desde el fin de la Guerra Civil española -en el año 1939-, por entender que su uso atentaba contra la unidad del país. Como consecuencia, desde finales de los años cincuenta se fue gestando la puesta en marcha de nuevas iniciativas editoriales que publicaron, libros y discos, exclusivamente en esta lengua.

Asimismo, puede considerarse que esta renovada industria fue uno de los factores que favoreció la entrada de la modernidad en Cataluña. Si bien ésta no se presentó en un principio como un proyecto estético unitario, a medida que se fue consolidando aplicó una imagen en la línea de la modernidad internacional, acercándose a finales de los sesenta a la estética del Pop y alejándose del abstraccionismo lírico tan típico de los años cincuenta. Por ello, el lenguaje gráfico del estilo Pop, de clara influencia norteamericana, pasó a aplicarse en el diseño de portadas de libros, revistas y cubiertas de discos, pudiéndose afirmar que el estilo Pop se convirtió en la expresión gráfica de la resistencia cultural en catalán a partir del año 1968.

El presente artículo, una vez contextualizada la época a nivel internacional y local, se centra únicamente en el estudio y el análisis del diseño aplicado en la producción discográfica, especialmente en aquella vinculada con el fenómeno de la Nova Cançó. ${ }^{1}$ Curiosamente, la traducción al castellano de este término es el de Nueva Canción y remite, por tanto, al movimiento de la canción chilena que surgió en los años sesenta y se consolidó durante los años del gobierno popular. Aunque son varias las semejanzas que pueden establecerse entre ambos movimientos, este no es el objetivo de este artículo. El caso de estudio que se presenta a continuación es el de la consolidación del estilo Pop como expresión gráfica de la identidad catalana en su resistencia contra la dictadura, a través de un medio como fue el de la canción popular.

\section{DESARROLLO}

La metodología utilizada ha sido la de la investigación histórica, consistente en la combinación de la consulta de fuentes bibliográficas; la búsqueda de material gráfico a utilizar; y, por último el acceso a la historia oral a través de entrevistas y conversaciones con algunos de los protagonistas, como America Sanchez ${ }^{2}$ y Enric Satué ${ }^{3}$. El primero de ellos fue entrevistado en varias ocasiones -años 2007 y 2016 - y el segundo en el año 2011.

La hipótesis de la que se parte, plantea que Cataluña optó por un estilo expresivo, que puede ser definido como Pop, como expresión gráfica de su resistencia cultural, al igual que sucediera a finales de los sesenta en otros países europeos -como Polonia, Holanda o Francia- en los que fue utilizado como expresión del activismo político.

\section{Los años sesenta: movimiento, arte y diseño Pop}

La década de los sesenta representó, para buena parte de Occidente, el inicio de una época de desarrollo económico tras ser superada la posguerra. En Europa el período de reconstrucción había sido especialmente duro, 
marcado por la austeridad; por ello, una vez superado y gracias a la bonanza económica y al pleno empleo, se produjo un estado de euforia en el que la sociedad quiso olvidar el pasado reciente y afrontar los nuevos tiempos con un cambio en su estilo de vida. En este aspecto, el consumismo ejerció un papel importante ya que la revolución en hábitos y costumbres se produjo en el seno de la sociedad de consumo, y fue liderada por los jóvenes.

Se conoce a dicho fenómeno como movimiento Pop, el cual puede ser considerado como el fenómeno cultural más significativo de la segunda mitad del siglo xx. Se trató de una actitud y de un estilo de vida en donde la juventud, la buena imagen -new look-, y el consumismo se convirtieron en los valores en alza. Su origen debe situarse, por lo tanto, en el seno de las sociedades industrializadas y en el marco de una economía capitalista, siendo en Gran Bretaña y en los Estados Unidos donde tuvo un mayor arraigo; si bien puede afirmarse que fue Inglaterra quien lideró el movimiento Pop, con Londres como epicentro del fenómeno, y exportándolo al resto del mundo a mediados de los años sesenta4.

Asimismo, cabe destacar que en aquel momento la gente joven no solo demandaba productos nuevos sino también espacios nuevos donde adquirirlos; lugares donde la ambientación y la imagen tuvieran una presencia importante. Por ello, las nuevas iniciativas comerciales comportaron una interesante alianza entre consumo, arte y diseño, y las tiendas se convirtieron en el escaparate de las últimas tendencias no solo del diseño sino también del arte. Como resultado, el acto de ir de compras se convirtió en una experiencia excitante y estimulante. En palabras de la historiadora y comisaria del diseño, Lesley Jackson, "la moda de ir de tiendas o el ir de tiendas como una moda" (Jackson, 1998, p. 37).

En lo que respecta al ámbito artístico, puede considerarse la década de los 60 como un período único en la historia del arte debido a la gran cantidad de estilos que surgieron y coexistieron al mismo tiempo -Pop Art, Op Art, arte cinético, arte conceptual-. Una época de intensa actividad artística en la que según el crítico de arte Hugh Adams se asistió a la aparición de formas poco ortodoxas de expresión (Adams, 1984, p. 7); pero de entre todas ellas la que mejor reflejó el espíritu del momento y tuvo un mayor impacto fue sin duda el Pop Art. Hasta mediados de los años cincuenta, la escena artística internacional estuvo dominada por el expresionismo abstracto - primera vanguardia artística de origen norteamericano-. Sin embargo, hacia la segunda mitad de la década, aparecía un estilo figurativo de características totalmente opuestas con una propuesta artística totalmente nueva, en la que la cultura popular -entendida como la cultura urbana de producción masiva y no como la forma tradicional de cultura vernácula creada por el pueblo- se convertía en obra de arte. Se trataba del Pop Art, un arte iconográfico que trabajaba con material que había sido utilizado previamente, como signo; todos aquellos productos pensados para el consumo masivo de las sociedades industriales así como los mensajes diseñados para promover su compra, se incorporaron en la obra de arte. El Pop Art, por lo tanto, puede ser considerado como el arte de la industrialización, producto de una sociedad opulenta y, en consecuencia, tuvo un mayor impacto también en los países más avanzados y en donde la sociedad de consumo tenía una fuerte presencia, es decir, en Gran Bretaña y los Estados Unidos. En su origen, el Pop Art es británico, surgiendo como resultado de los debates llevados a cabo entre 1952 y 1955 por The Independent Group (Grupo Independiente) en el ICA -Instituto de Arte Contemporáneo de Londres-.
4. La revista Time en su edición del mes de abril del año 1966, publicaba un artículo titulado “London: The Swinging City" término con el que se conoció el boom consumista que vivió la capital inglesa. Gracias a este artículo, el movimiento Pop se exportó fuera de las fronteras británicas. 
Dicho grupo estaba compuesto por artistas -entre los que destacan Richard Hamilton (1922-2011) y Eduardo Paolozzi (1924-2005)-; críticos de arte Lawrence Alloway (1926-1990) y Reyner Banham (1922-1988)-; arquitectos y fotógrafos -como por ejemplo Nigel Henderson (1917-1985)-; y los temas sobre los que debatían trataban sobre la relación del hombre y las máquinas, 0 sobre el american way of life -el modelo de vida (norte)americano- y la cultura popular. Fue precisamente Alloway quien en 1954 utilizó por primera vez el término Pop Art durante el transcurso del debate sobre este último tema. Sin embargo, fueron los norteamericanos quienes popularizaron el Pop Art gracias a figuras como Andy Warhol (1928-1987) o Roy Lichtenstein (19231997) entre otros, desembarcando en Europa el año 1964 al ser concedido a Robert Rauschenberg (1925-2008) el Gran Premio de la XXXII Edición de la Bienal de Venecia. Pero en Europa, a principios de los sesenta surge una variedad de estilos figurativos en respuesta a la abstracción que había dominado el panorama artístico. Si bien esta puede ser considerada como la versión europea del Pop Art -desde un punto de vista formal y por la utilización de imágenes procedentes de la cultura popular-, las intenciones de los artistas europeos fueron más allá de las de los británicos o de la simple aceptación de la sociedad de consumo y el american way of life. En las propuestas de países como Alemania, Francia, Italia o España era evidente la crítica política y social, reflejo de las diferentes y difíciles coyunturas vividas tras la Segunda Guerra Mundial.

En lo que respecta al diseño gráfico, a finales de los años cincuenta se desarrolló un nuevo estilo de rasgos claramente expresivos, que puede ser reconocido como estilo Pop. Consistía en una nueva variante del lenguaje gráfico moderno que sería utilizado por la publicidad, para dar respuesta a las nuevas necesidades comunicativas generadas en el nuevo contexto de recuperación económica. Ante la creciente sociedad de consumo el mercado necesitaba, además de productos, vender también sensaciones para generar, a su vez, nuevas necesidades; por tanto, se trataba de vender significados, por lo que los mensajes debían ser mucho más subjetivos y simbólicos. Y fue el estilo Pop el que supo generar nuevas soluciones gráficas, ayudado por la ciencia de la semiótica.

La nueva propuesta formal fue lanzada por los Estados Unidos al resto del mundo de la mano de Push Pin Studios -liderados por Milton Glaser (1929) y Seymour Chwast (1931)- entre otros. El suyo era un estilo heredero de los pioneros modernos norteamericanos que, entre otras cosas, revisaba y reinterpretaba la historia de la comunicación visual y, por lo tanto, se rebelaba en contra de un Movimiento Moderno -representado por la escuela suizaque se había manifestado abiertamente antihistórico y contrario a la tradición. Porque si el estilo Pop destacó por alguna cosa fue por la recuperación y la reinterpretación de la historia de la comunicación visual. El diseñador pop se transformó en historiador y al mismo tiempo en revitalizador, identificando los rasgos formales de estilos del pasado y, por ello, se apropió de su iconografía interpretando también sus valores estilísticos.

En este sentido, el diseño pop mostró especial interés por el Art Nouveau del cual adoptó la línea orgánica, la tipografía gestual y caligráfica, y los detalles ornamentales. Se interesó por algunas de las vanguardias artísticas como el dadaísmo, el surrealismo, el fauvismo y el futurismo, así como por la fantasía y las formas geométricas del Art Déco; se fijó en algunos 
aspectos del arte tradicional de culturas como la antigua Persia, la India o el Japón; y, por último, incorporó elementos de la cultura popular, como por ejemplo el lenguaje gráfico del cómic. Todo ello configuró un estilo que destacó por el uso de la ilustración como principal elemento transmisor de ideas y de conceptos; reivindicando de nuevo la hegemonía de la ilustración, ahora renovada, después de que fuera sustituida por la fotografía a finales de los años treinta. El estilo Pop destacó también por el uso de la tipografía como forma visual y por la experimentación con las formas de las letras, con lo que el diseñador se rebeló contra las reglas tipográficas tradicionales, en especial las del Estilo Tipográfico Internacional -la escuela suiza- para el que la tipografía debía ante todo ser legible y permitir la comunicación. Y por último, se distinguió también por la aplicación de una amplia y vibrante gama cromática.

En Europa una gráfica de estas características se expandió de la mano de la industria cultural norteamericana y británica, en forma de cubiertas de discos, portadas de revistas y pósteres de grupos musicales. Sin embargo, y al igual que sucediera con la versión europea del Pop Art, se vinculó también con los movimientos de protesta y contraculturales de finales de los sesenta; una gráfica de estas características sirvió para comercializar ideas, no mercancías. Es el caso de Polonia y, posteriormente coincidiendo con la crisis de Mayo del 68, de países como Francia y Holanda que aplicaron un estilo similar en su gráfica de protesta.

\section{Los sesenta en España y Cataluña}

En el caso de España, la llegada de los sesenta representó también la de un cierto crecimiento económico, pero sin olvidar que el país se hallaba gobernado desde el fin de la Guerra Civil por una dictadura militar, y que las dos décadas precedentes habían estado marcadas por la autarquía y el estancamiento económico. La década de los sesenta es conocida como la etapa del "desarrollismo" en la que, gracias al Plan de Estabilización Económica de 1959 y a las medidas económicas puestas en marcha, la sociedad española vio aumentar su renta y comenzó a gozar de un cierto poder adquisitivo. Como consecuencia, la clase trabajadora empezó a cambiar sus costumbres y ya no solo compraba productos de primera necesidad sino también televisores, coches, refrigeradores y lavadoras; en definitiva, había hecho su aparición una cierta clase media. Sin embargo, este desarrollo económico no comportó ningún intento de liberalización política por parte del gobierno sino todo lo contrario, acciones y medidas represivas continuaron siendo las señas de identidad del régimen; el fascismo había querido mostrarse al exterior como una democracia gracias a este resurgir económico pero no se había dado el paso.

A pesar de ello, Cataluña y, más en concreto, su capital Barcelona, durante esta década vivió un interesante momento a nivel social y cultural en el que se dio entrada a las ideas, tendencias, modas y costumbres en la línea del movimiento Pop, todas ellas claramente enfrentadas a la mojigatería franquista dominante. Si Londres era el epicentro del Pop internacional, Barcelona se convirtió a finales de los sesenta en el enclave Pop de España. La entrada del movimiento Pop fue posible, en parte, gracias a que una importante y renovada industria cultural se puso de nuevo en marcha como una forma de oposición pacífica contra el régimen franquista. 

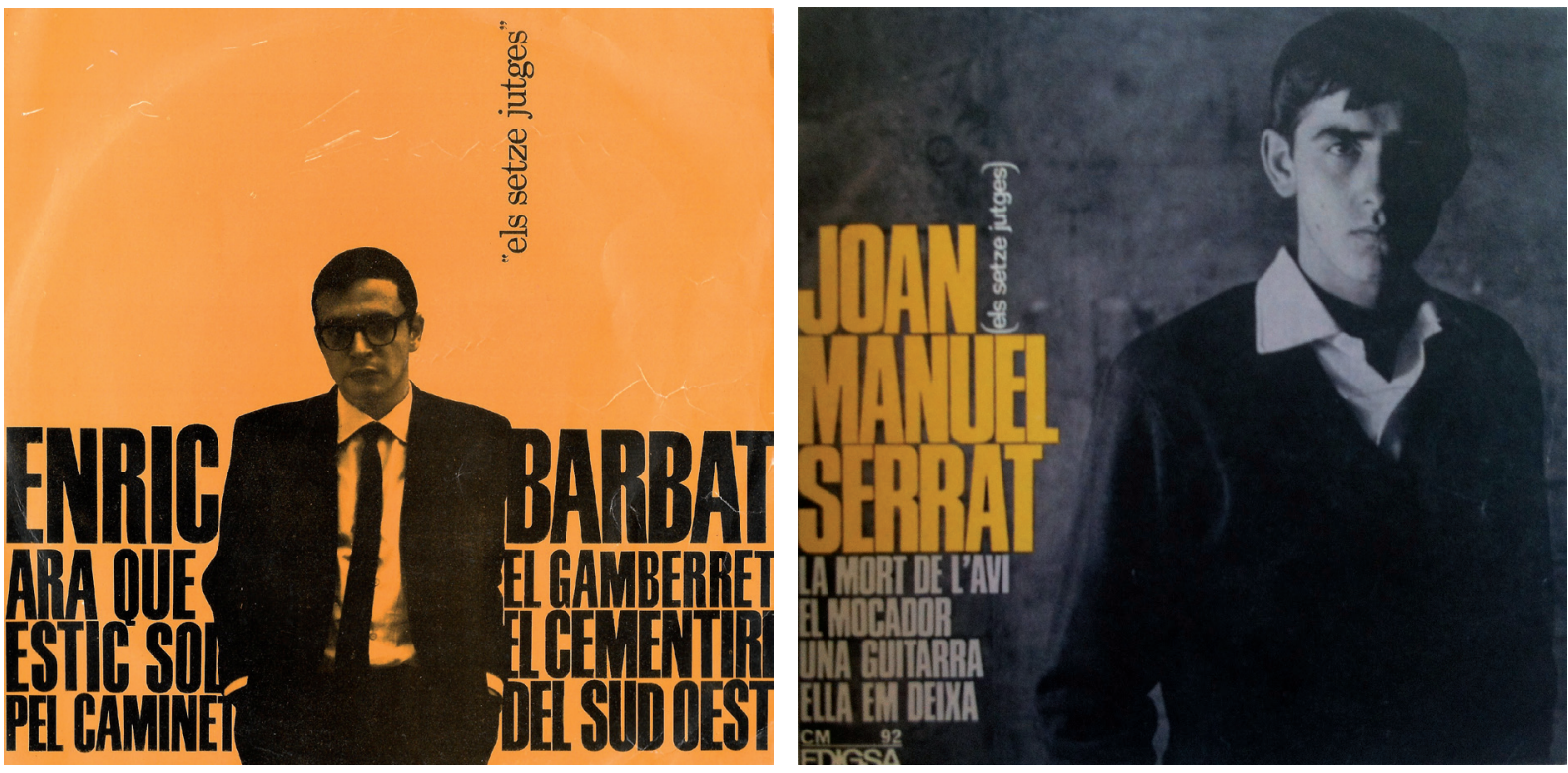

Figura 1. Diseños realizados por Fornas en la primera etapa de Edigsa para: Fig. 1.1. Enric Barbat (1964), Fig. 1.2. J. M. Serrat (1965). Fuente: colección particular

5. De entre los miembros de la Nova Cançó destacan: Joan Manuel Serrat, Maria del Mar Bonet, Lluís Llach i Raimon, entre otros.

6. La traducción al castellano del título Ens calen cançons d'ara correspondería a "Necesitamos canciones de ahora"; artículo que ha pasado a ser considerado el texto fundacional del movimiento de La Nova Cançó.

\section{La Nova Cançó catalana}

En la década de 1960 puede decirse que la canción es el elemento cultural de masas más universal, más poderoso y más temido

(Vázquez Moltanbán, 1968, p. 90).

A finales de los años cincuenta surgía en Cataluña un movimiento artístico vinculado a la música popular, conocido como la Nova Cançós. Su objetivo principal era defender la lengua catalana y su uso en el mundo de la canción. El término fue utilizado por primera vez por el escritor Lluís Serrahima en el artículo Ens calen cançons d'ara, aparecido en la revista Germinàbit en el año $1959^{6}$, y en poco tiempo, el éxito de la Nova Cançó fue tan rotundo que se convirtió en un fenómeno artístico, cultural, cívico y social. La canción popular se había convertido en el medio más eficaz de difusión del catalán. Los impulsores de la Nova Cançó fueron personas pertenecientes a la burguesía intelectual barcelonesa y músicos aficionados. Posteriormente se incorporaron los que sí querían ser cantantes, quienes procedían de diversos estratos sociales y diferentes niveles culturales. La clave de su éxito residió en que todos ellos estaban muy sensibilizados con el objetivo del movimiento, además de ser personas muy combativas.

Cabe destacar también que coincidiendo con la aparición de la Nova Cançó se inició una nueva etapa en el estilo gráfico aplicado a las cubiertas de discos: que pasaron a ser tan importantes como los discos que contenían. Hasta ese momento, las cubiertas de los discos publicados en el mercado español habían sido diseñadas con un estilo de aire tradicional en donde el principal recurso gráfico utilizado era la fotografía a color de los intérpretes junto con tipografía informativa para el título del disco. En un principio, los referentes en su diseño se encontraron en la canción francesa, tan de moda desde los años cincuenta entre la intelectualidad catalana. No obstante, en la década siguiente fueron los ritmos anglosajones los que marcaron una 
nueva tendencia; si con Elvis Presley se había producido un cambio en lo que a términos musicales se refiere, con la irrupción de Los Beatles fue la concepción gráfica de la producción discográfica la que se vio afectada. Por tanto, el estilo Pop hizo su irrupción en el mercado catalán de la mano de los éxitos internacionales de la música pop anglosajona, convirtiéndose en fuente de inspiración y en modelo a imitar.

"El Pop representa la entrada de modelos foráneos, es en cierta forma una manifestación de colonialismo cultural. Pero al mismo tiempo genera una versión típicamente local" (Guillamon, 2004, p. 2).

Pero si la Nova Cançó consiguió romper el silencio que el franquismo impuso a la lengua y la cultura catalanas fue en parte gracias al apoyo que tuvo de los medios de comunicación -en especial de la radio- y del sector empresarial. La creación de sellos discográficos surgidos con la intención de publicar exclusivamente discos en catalán fue decisiva en este sentido. Se trataba de las discográficas Edigsa, Concéntric y Pu-put!

\section{Edigsa}

El 29 de mayo de 1961 nacía la discográfica Edigsa -Editora General S.A.--, la primera editora exclusiva de discos en catalán y principal plataforma de difusión de la Nova Cançó. Edigsa contó con un amplio catálogo de grupos y de intérpretes en donde, además de la canción de autor, estuvieron presentes otros géneros artísticos.

En cuanto a su imagen gráfica, la dirección de Edigsa puso todos los medios necesarios para que el nuevo sello fuera sinónimo de calidad artística y de modernidad; para ello contrató al diseñador barcelonés Jordi Fornas (19272011). Puede afirmarse que Fornas fue el canal de entrada de la imagen moderna de la Europa de los sesenta en el sector discográfico y editorial catalanes, ya que participó también en otros proyectos culturales en catalán -la editorial Edicions 62, la revista Serra d'Ory la Enciclopèdia Catalana-, creando un estilo propio de gran influencia en la época.

Fornas optó por el uso de una fotografía del intérprete o grupo, en blanco y negro, de estilo periodístico, y la dispuso ocupando el espacio total de la composición. Gracias a este único recurso, las cubiertas de Edigsa pasaron a tener un aire renovado, diferenciándolas de las del resto de las discográficas españolas. Para la realización de las fotografías, contó con la colaboración de algunos de los fotógrafos catalanes más reconocidos del momento, como Oriol Maspons (1928-2013) y Colita (1940). También aplicó un alto contraste a la fotografía, obteniendo como resultado la imagen quemada7. En cuanto a la composición del texto, el signo más representativo fue la composición de tipografía Sans Serif en movimiento -principalmente por las tipografías Folio y Helvética, esta última puesta a disposición de los estudios gráficos españoles gracias a la reciente llegada del catálogo Letraset-.

Pero a finales de los sesenta, Fornas decidió cambiar el estilo e incorporar los rasgos característicos del Pop. En Tots som pops (1969) del grupo La Trin$c a^{8}$ se puede apreciar el cambio, con una clara influencia de la gráfica norteamericana, el Pop y la psicodelia; mientras que en Festa Major (1970), Fornas conjugó la imagen quemada con la adaptación de la tipografía a formas orgánicas neoliberty que dominaban el conjunto de la composición.

El resultado mostraba una clara influencia de la psicodelia, tanto por el estilo del dibujo como por los vivos colores aplicados.
7. Resultado obtenido mediante la utilización de películas ortocromáticas, un resultado similar al obtenido mediante la aplicación de la técnica de posterización con PhotoShop.

8. La Trinca, grupo de canción popular catalana que destacó por criticar al régimen franquista utilizando el humor en las letras de sus canciones. 

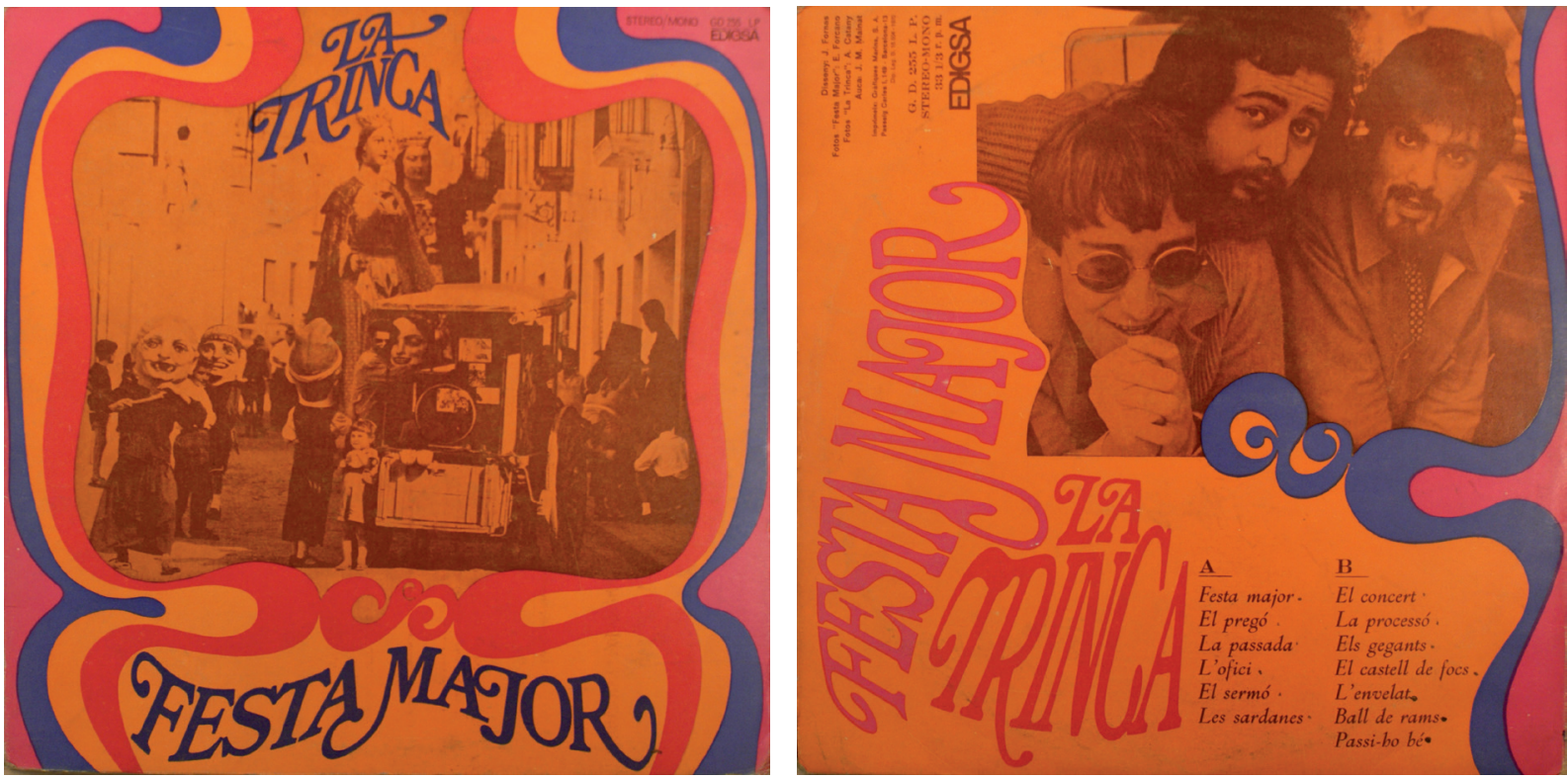

Figura 2. Diseño realizado por Fornas en la segunda etapa de Edigsa para La Trinca: Festa Major (1970) (cara y dorso). Fuente: colección particular.

9. Push Pin Style, término con el que se reconoce al estilo desarrollado por Push Pin Studios en los años sesenta, el cual se caracteriza por conjugar un gran dominio del dibujo, una gran habilidad para la ilustración creativa y un gran sentido del humor.
En otras ocasiones, las cubiertas fueron diseñadas por jóvenes diseñadores que empezaban a destacar en el ámbito del diseño gráfico catalán, como por ejemplo el argentino Juan Carlos Pérez Sánchez (Buenos Aires, 1939) conocido como America Sanchez a partir de 1980-. Suyo es el diseño de la cubierta de A collir pebrots (1970), compuesta por una ilustración central sobre fondo blanco, el dibujo de dos pimientos rojos y el nombre del grupo en letra caligráfica. El diseño recuerda al que Warhol hiciera para la cubierta de The Velvet Underground e Nico (1967), no por la técnica utilizada por Sanchez, similar al estilo de dibujo Push Pin Style ${ }^{9}$, sino por la composición y los elementos utilizados. En este caso, el diseñador argentino substituyó el plátano por unos pimientos -que en catalán tienen el mismo doble sentido que el plátano-. Cabe destacar que la aportación de America Sanchez en la historia del diseño gráfico catalán ha sido fundamental desde su llegada a Barcelona, el año 1965. Desde el primer momento fue muy bien acogido en la capital catalana; en palabras del propio Sanchez, los trabajos que trajo consigo fueron considerados como extraordinarios en comparación con el de gran parte de los diseñadores españoles de la época. A su arribo, traía consigo la experiencia profesional en una de las agencias de publicidad más importantes en la historia reciente de Argentina, Agens, además de un gran bagaje cultural y un amplio conocimiento del panorama artístico y gráfico internacional, gracias a la modernización cultural vivida en la Argentina de los sesenta impulsada por el Instituto Torcuato Di Tella -ITDT-. Todo ello hizo que, en poco tiempo, se convirtiera en un referente del diseño gráfico barcelonés.

\section{Concèntric}

El año 1964 se creaba Concèntric, fruto de la escisión de Edigsa. Concètric nació con la misma vocación inicial que Edigsa, pero mostrando un especial interés por llegar a un público más joven y diverso. La aparición de una nueva discográfica, en este caso competidora de Edigsa, representaba que el proceso de normalización se había puesto en marcha; la suma de esfuerzos paralelos sería útil en la consecución del objetivo final. 

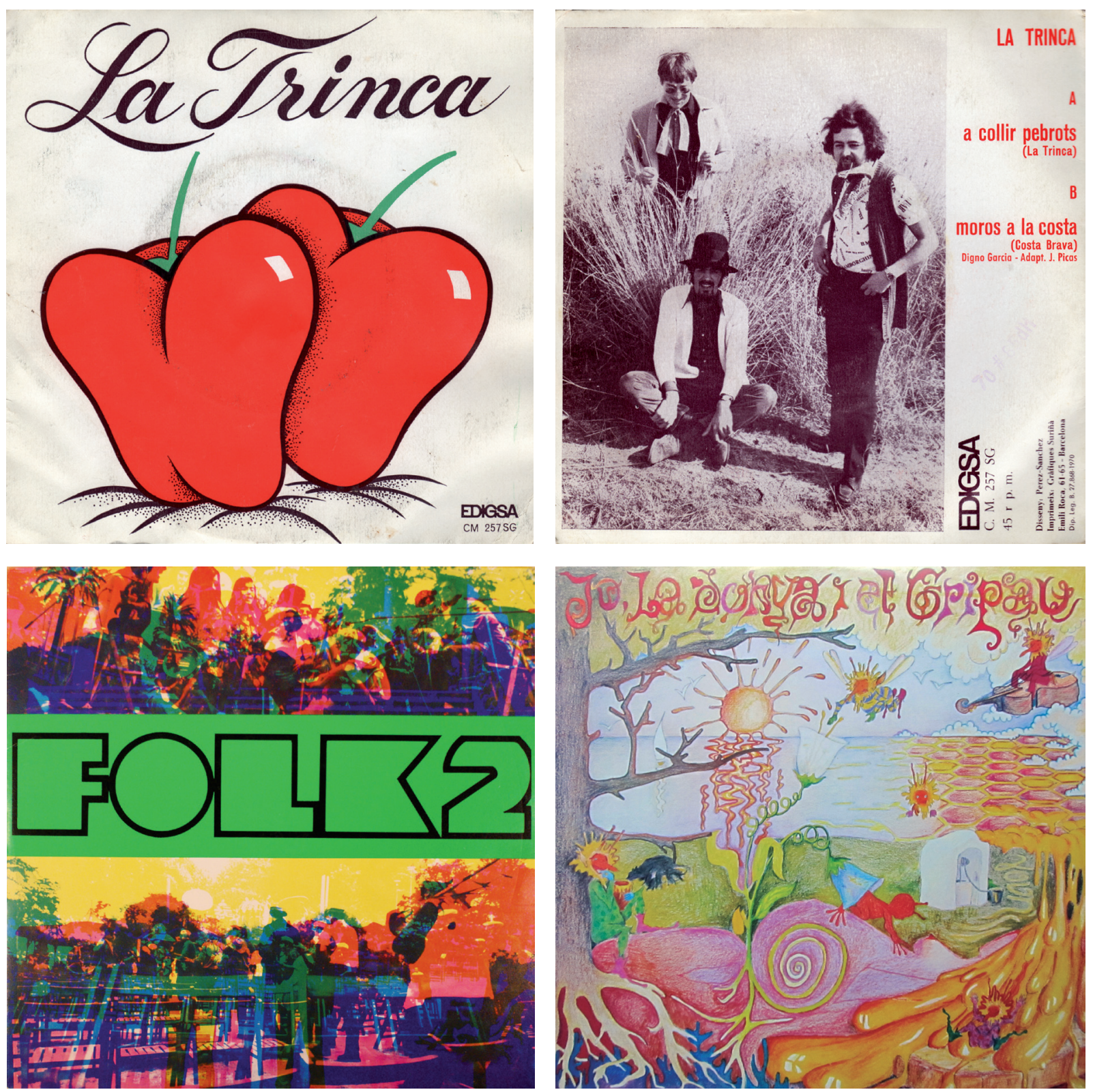

Concèntric quiso presentarse también como un sello moderno. Prueba de ello es el diseño de su identidad gráfica, la imagen geometrizada de uno de los símbolos de la iconografía catalana, el dragón, obra del escultor Josep Maria Subirachs (1927-2014), diseñado en el año 1963.

Como diseñador gráfico del sello se contrató a Pau Riba (Palma de Mallorca, 1948), músico fundador de Grup de Folk, uno de los grupos de la discográfica y máximo representante de la música progresiva de los setenta. Personaje polifacético -nieto del poeta catalán Carles Riba-, Pau Riba había estudiado grafismo en la Escuela Massana de Barcelona y por ello se le consideró idóneo para el diseño de la discográfica.

Conocedor de los estilos y las modas que dominaban el panorama gráfico internacional, incorporó en sus diseños desde los rasgos del Pop y el
Figura 3. Diseño de America Sanchez para La Trinca, A collir pebrots (1970) (cara y dorso). Fuente: colección particular

Figura 4. Diseños realizados por Pau Riba para discos propios: Fig. 4.1. Folk 2 (1968), Fig. 4.2. Jo, la donya i el gripau (1971). Fuente: colección particular. 
Figura 5. Diseño realizado por Enric Sió para Guillermina Motta, Visca l'amor (1968). Fuente: colección particular.

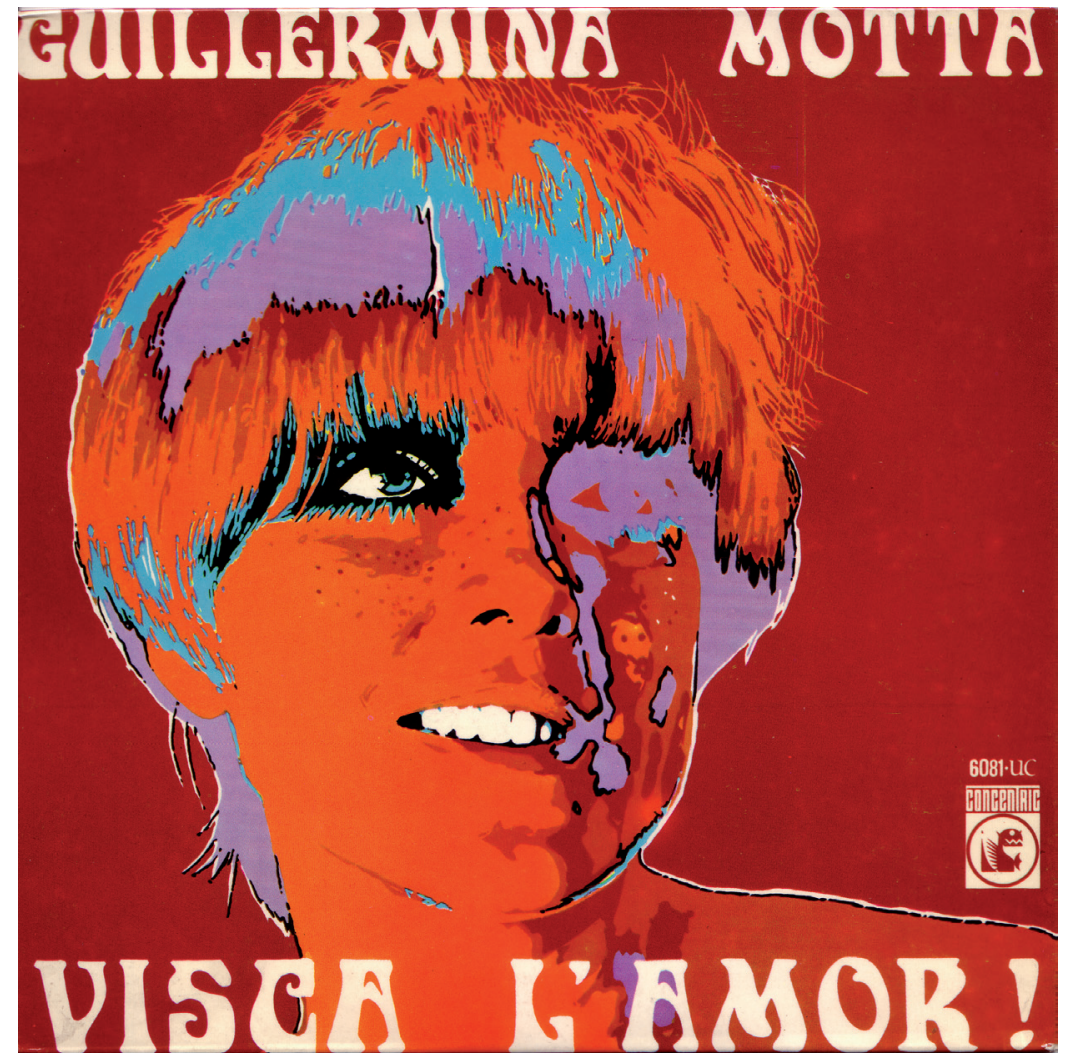

cromatismo de la psicodelia, hasta la imagen conceptual típica de los años setenta. Uno de sus diseños que merece destacarse es Taxista (1967), disco suyo en solitario para el que utilizó una fotografía de él mismo recostado tocando la guitarra, fotografía que destacaba no solo por su riqueza cromática sino también por el plano desde la que se había captado. Asimismo, encajó el texto en el espacio delimitado por la imagen a la manera como el artista de la psicodelia, Wes Wilson, lo estaba haciendo en la Costa Oeste de los Estados Unidos, rotulando la letra con formas orgánicas y ondulantes.

Al igual que en Edigsa, Pau Riba no fue el único responsable del diseño de Concèntric; otros diseñadores catalanes colaboraron con el sello hasta su cierre en el año 1973. Uno de ellos fue el dibujante de cómic y publicista barcelonés Enric Sió (1942-1998), de quien destaca el diseño de Visca l'amor (1968) de la cantante Guillermina Motta, protagonista y heroína de alguno de sus cómics.

\section{Pu-put!}

El año 1977, en plena etapa de transición hacia la democracia -Franco falleció el año 1975-, el sello madrileño Zafiro fundó una nueva discográfica de nombre Pu-put!, para aprovechar el éxito de la Nova Cançó. El compositor y productor musical Antoni Parera fue elegido para dirigir la discográfica y decidir los grupos y géneros musicales a publicar. No se trataba de competir con Edigsa y Concèntric sino de dar salida a grupos jóvenes que no eran conocidos todavía, así como recuperar temas y géneros musicales como el 

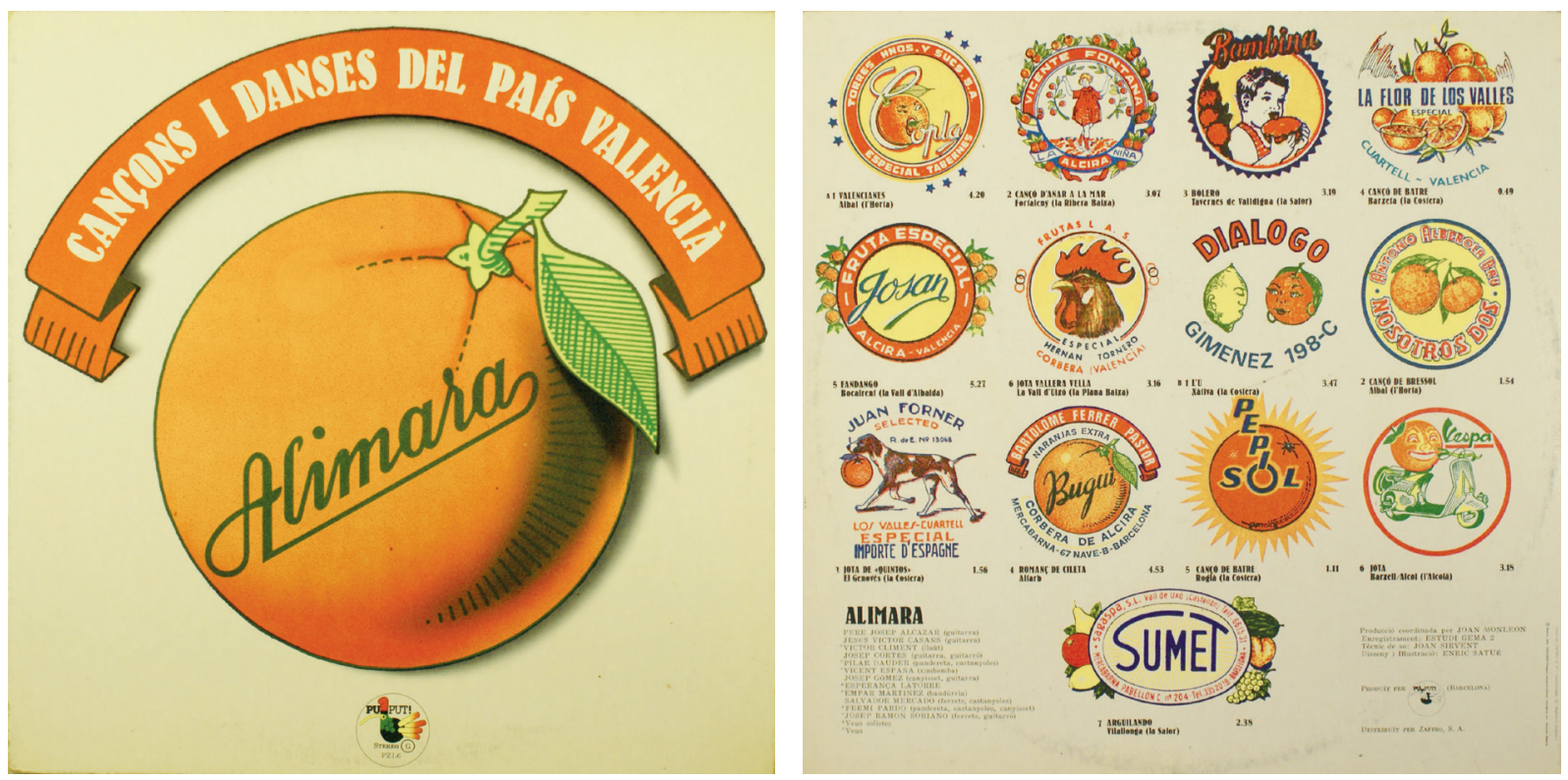

folclore o la revista musical. En realidad, se trataba de sumar esfuerzos. De 1977 al año de su cierre en 1981, la discográfica editó álbumes de gran calidad y con una interesante imagen gráfica, obra del diseñador catalán Enric Satué, a quien Parera eligió como responsable de la imagen. Enric Satué (Barcelona, 1938) quiso abrir un espacio diferente que no compitiera con los otros sellos discográficos y por ello desarrolló para Pu-put! una variante del estilo Pop muy interesante; en palabras del propio Satué, "a medio camino entre el pop californiano y la tradición de los ilustradores catalanes" (Gámez, 2008, p. 16), en la que combinó una clara influencia norteamericana con la tradición catalana de principios del siglo XX; estilo que ha pasado a ser considerado como la versión autóctona de la gráfica Pop, recibiendo el calificativo de neo-noucentisme (Calvera, 1996). No fue esta la primera vez en la que Satué aplicó esta versión del Pop "a la catalana". Gran conocedor y seguidor de los trabajos de Milton Glaser y los Push Pin Studios, tras aplicar un estilo Pop de clara influencia norteamericana en el sector editorial -uno de sus trabajos más importantes fue el diseño de la revista CAU, Construcción Arquitectura Urbanismo, de 1970 a 1974-, en el año 1976 empezó a desarrollar el "neo-noucentisme" en el diseño de las portadas de libros de la colección Biblioteca de divulgación política de la Editorial La Gaya Ciencia. Su decisión fue la de pasar revista a los símbolos e íconos de la catalanidad popular tratados con los rasgos característicos del pop, es decir: dibujo a la manera Push Pin Style, colores muy vivos, incorporación de elementos procedentes de la cultura pop apostando para el texto por la Bernhard Antiqua, tipografía diseñada por Lucian Bernhard en 1912 y que fue ampliamente utilizada por la gráfica catalana de los años veinte y treinta. Posteriormente, una nueva generación de diseñadores gráficos entre los que se hallaría la madrileña Pilar Villuendas (1945)- aplicaría esta versión autóctona del Pop como expresión gráfica del discurso político de la transición hacia la democracia.
Figura 6. Diseño realizado por Enric Satué, Cançons i danses del País Valencià (1978) (cara y dorso). Fuente: colección particular. 

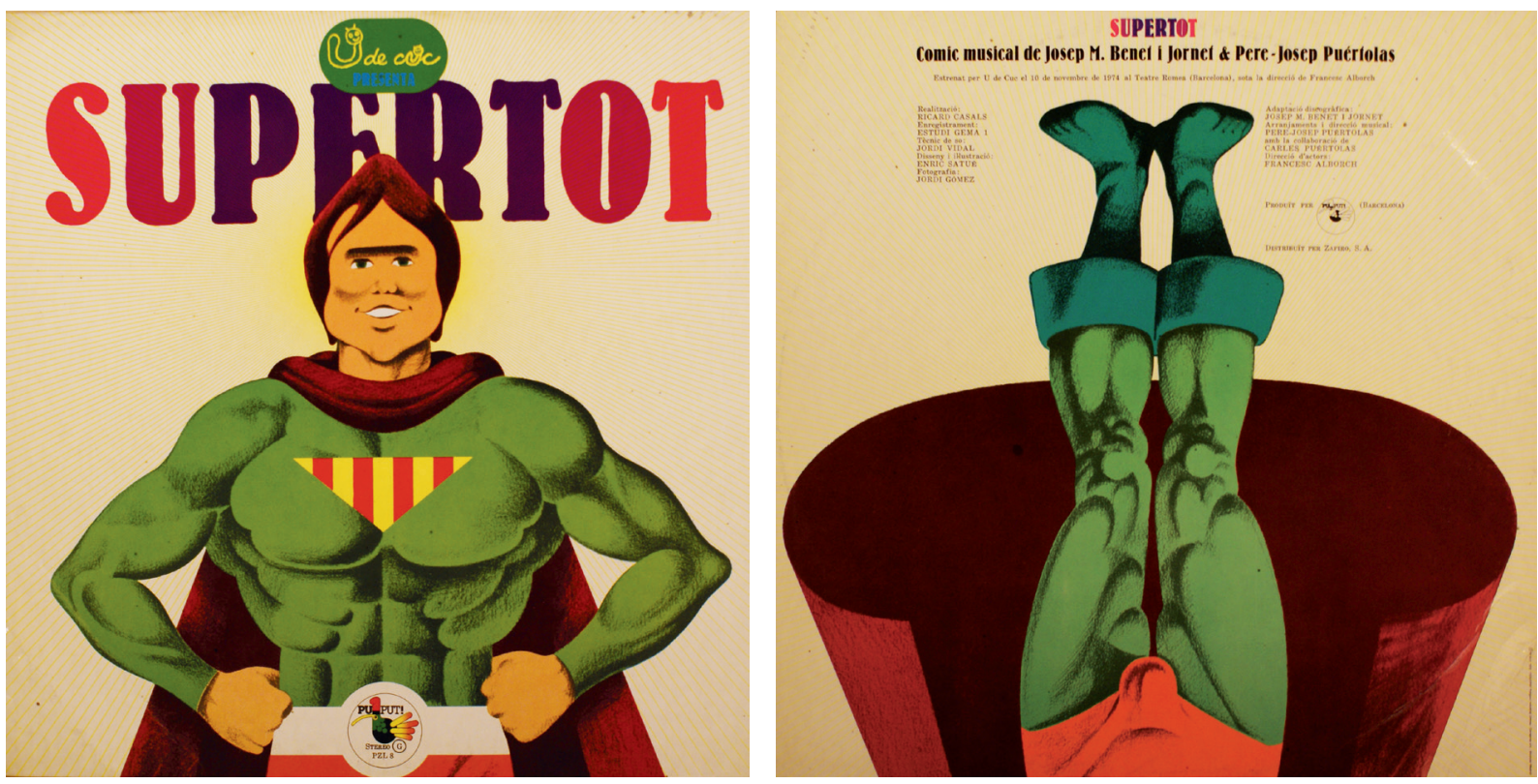

Figura 7. Diseño realizado por Enric Satué, Supertot (1978) (cara y dorso). Fuente: colección particular.
Volviendo al caso de Pu-put!, de entre las cubiertas que diseñó Satué destaca el disco Supertot (1978) para la que se inspiró en el mundo del cómic diseñando un "Superman a la catalana".

\section{Otras discográficas... en catalán}

Edigsa, Concèntric y Pu-put! no fueron las únicas discográficas en publicar en catalán. Es el caso de la discográfica Discophon, concesionaria del sello CBS en España que, durante los años sesenta y setenta publicó grupos y solistas catalanes con la intención de darlos a conocer internacionalmente. De entre los cantantes que publicaron, destacaron principalmente los cantautores valencianos Raimon y Ovidi Montllor; mientras que para el diseño de las cubiertas de estos dos cantautores se eligió a los valencianos Equipo Crónica -los principales representantes del Pop Art español-. Conocidos por hacer una dura crítica del franquismo a través de sus obras, Equipo Crónica hizo lo mismo en las cubiertas para Discophon.

\section{Para finalizar}

La Nova Cançó siguió viva hasta principios de los años ochenta, momento en que entró en una profunda crisis de la que no pudo salir. Las discográficas del género cierran sus puertas: en 1973 lo hizo Concèntric, en 1981 Pu-put! y en el 1983 Edigsa. Una vez perdido su carácter reivindicativo no pudo sobrevivir a la desafección mostrada tanto por los medios de comunicación como por el propio gobierno catalán.

\section{CONCLUSIONES}

El estudio realizado del diseño de las cubiertas de discos del fenómeno conocido como la Nova Cançó ha permitido demostrar que efectivamente en Cataluña se aplicó una gráfica que, de acuerdo con la definición que se ha dado de esta, puede ser considerada como Pop y, por tanto, este estilo se convirtió en la expresión gráfica de la resistencia cultural catalana. Porque, tal como se ha anotado al principio, si bien el dominio de la presente 


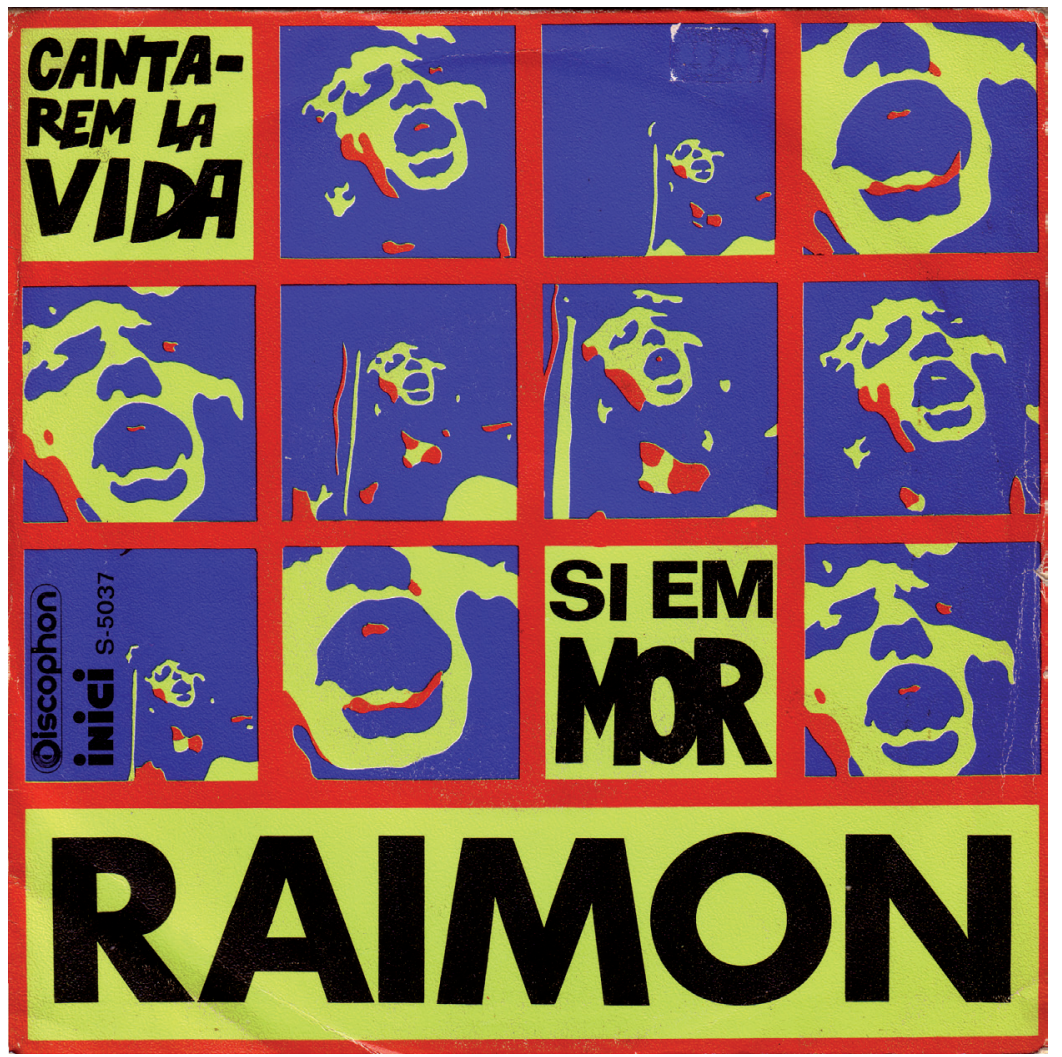

Figura 8. Diseño realizado por Equipo Crónica para Discopohon y el cantautor Raimon, 1968. Fuente: colección particular.

Figura 9. Diseño realizado por Equipo Crónica para Discopohon y el cantautor Raimon, 1968. Fuente: colección particular.

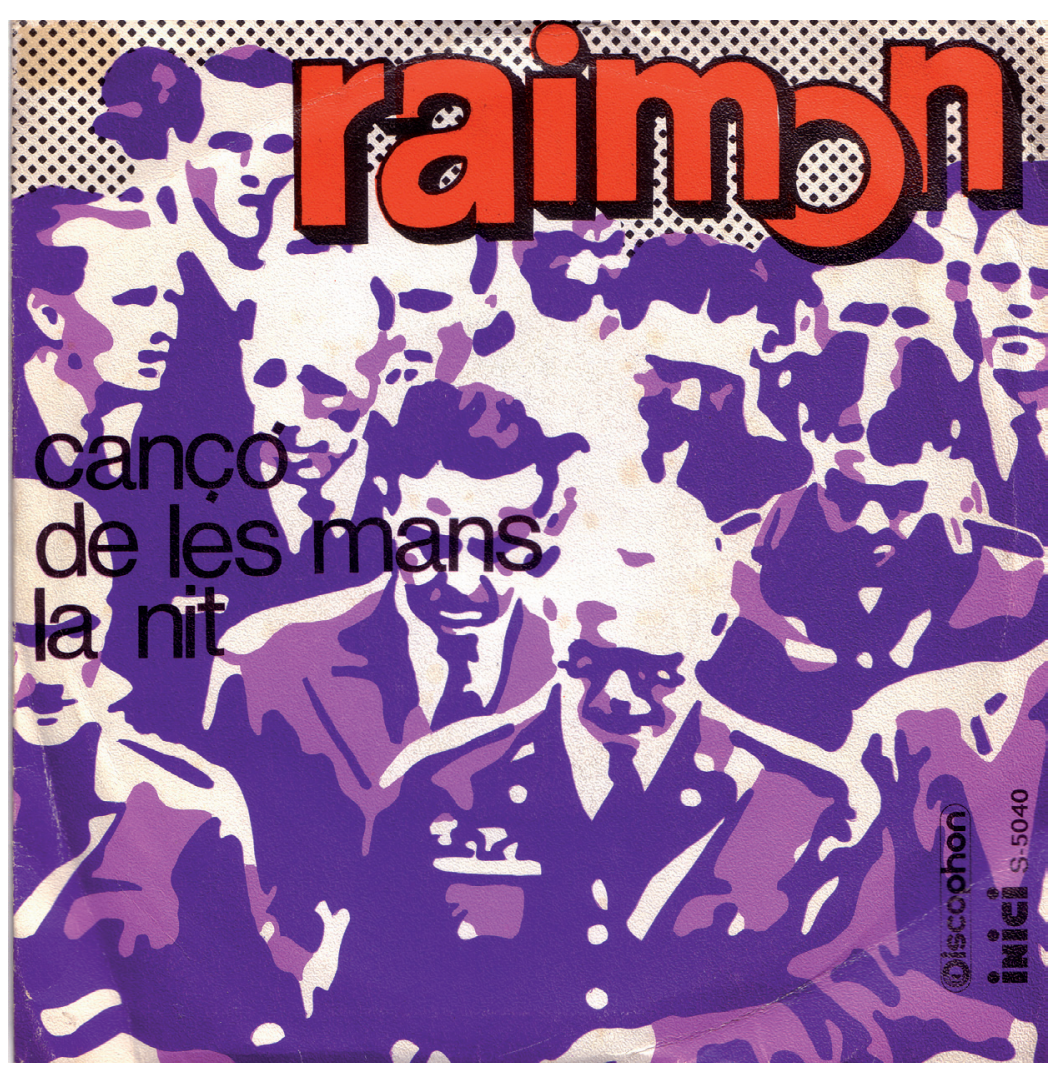


investigación se ha centrado en la industria discográfica, esta ha servido de ejemplo destacable de lo que sucedió en la industria cultural que editó y publicó exclusivamente en lengua catalana como forma de oposición pacífica al régimen de Franco. Por lo tanto, Cataluña optó por un estilo que en su origen había sido utilizado en Estados Unidos y en Gran Bretaña como expresión gráfica de los nuevos mensajes comerciales en un contexto, el de los años sesenta, en donde además de vender mercancías se necesitaba vender significados. Pero al igual que sucediera con el Pop Art en algunos países europeos, la expresión gráfica del Pop fue utilizada por la resistencia cultural -el caso catalán-, el activismo político -Polonia y Francia- y los movimientos contraculturales de final de década -Holanda y el movimiento Provo-. Asimismo, se ha demostrado también que el estilo Pop aplicado en la discográfica catalana evolucionó de una primera versión todavía no muy desligada del estilo suizo -las primeras portadas de Jordi Fornas para Edigsa-, a una clara influencia del Pop norteamericano -destacando la aportación de America Sanchez y Enric Satué- y de las últimas tendencias artísticas internacionales -de la mano de Pau Riba y Enric Sió-; para, finalmente, derivar en una versión autóctona que la Dra. Anna Calvera denominó “neo-noucentisme", que fue desarrollada por Enric Satué y de la que él reclama la paternidad -en la entrevista mantenida en su estudio en el año 2011-. Esta versión autóctona del Pop pasó a aplicarse no tan solo en la industria cultural sino también en el discurso político y en las reivindicaciones de una sociedad que avanzaba hacia la democracia. 


\section{Bibliografía}

Adams, H. (1984). Art of the Sixties. London: Peerage.

Banham, R. (1996). A Critic Writes. Selected Essays by

Reyner Banham. Eds. Mary Banham, Sutherland Lyall,

Cedric Price, Paul Barker. Berkeley: University of

California Press.

Baynes, K., y Baynes, K. (1966). Behind the scene. Design Journal, (212) 18-29.

Burke, P. (2009). Popular culture in early modern Europe. Farnham, England; Burlington, VT: Ashgate.

Calvera, A. (1996). Elisava fa 35 anys. Anys de debat sobre la idea de disseny. Temes de Disseny, (13).

Calvera, A. (2007). Pioneros. Notas en torno al nacimiento de una profesión. En: Gil, E. (Ed.) (2007). Pioneros del diseño gráfico. Barcelona: Index Book.

Calvera, A. (Ed.) (2014). La formació del sistema disseny Barcelona (1914-2014), un camí de modernitat: assaigs d'història local. Barcelona: Universitat de Barcelona, Publicacions i Edicions.

Collins, B. R. (2012). Pop Art: the independent group to Neo Pop, 1952-90. London: Phaidon.

Cubeles i Bonet, A.; Ruiz, I.; Planas, X.; Aymerich, P. (Eds.). (2010). La Nova cançó: la veu d'un poble. Museu d'Història de Catalunya, 4.06-31.10, 2010. Barcelona: Generalitat de Catalunya, Departament de Cultura i Mitjans de Comunicació.

Fortea Castillo, M. (2015). El Pop a la manera del disseny gràfic català. El descobriment Pop del passat: dissenyadors - col•leccionistes (Doctorado). Universitat de Barcelona. Departament de Disseny i Imatge.

Gámez, C. (2008). Cançoníssima. Dies de vinil i cançons. Folleto de la exposición celebrada en Octubre. Centro de Cultura Contemporánea de Valencia, 18.09-26.10, 2008. Valencia: Fundació Josep Renau.

Guillamon, J. (2004). El pop catalán: una edad de oro. La Vanguardia, 1 de julio, p. 2.

Huertas, J. M. (1966). Nova Cançó, Nova Cultura. El 19 de diciembre se cumple cinco años del nacimiento de "Els Setze Jutges". Destino, (1528), 22.

Jackson, L. (1998). The sixties: decade of design revolution. London: Phaidon Press.

Mallofré, A. (1966). “Setze Jutges”, canción catalana y algunas necesarias consideraciones elementales. Destino, (1531), 90.

Margolin, V. (2015) World History of Design. London: Bloomsbury Academic.

Satué, E. (1988). El diseño gráfico: desde los orígenes hasta nuestros días. Madrid: Alianza Ed.
Satué, E. (1987). El disseny gràfic a Catalunya. Sant Cugat del Vallès, Barcelona: Els llibres de la frontera.

Vázquez Montalbán, M. (1968). Antología de la Nova Cançó catalana. Barcelona: Ediciones de cultura popular. 